See discussions, stats, and author profiles for this publication at: https://www.researchgate.net/publication/344153954

\title{
Synthesis of Novel Benzimidazolium Gemini Surfactants and Evaluation of Their Anti-Candida Activity
}

Article in ACS Omega · July 2019

Dol: 10.1021/acsomega.9b01056

CITATIONS

6

7 authors, including:

Faroog Wani

Jamia Millia Islamia

13 PUBLICATIONS 55 CITATIONS

SEE PROFILE

sis.

Babita Aneja

Jamia Millia Islamia

22 PUBLICATIONS 139 CITATIONS

SEE PROFILE
READS

39

Amad Uddin

Jamia Millia Islamia

10 PUBlications 23 CITATIONS

SEE PROFILE

Gerard Sheehan

University of Birmingham

28 PUBLICATIONS 185 CITATIONS

SEE PROFILE

Some of the authors of this publication are also working on these related projects:

Project Medicinal Chemistry View project

Project Molecular docking View project 


\title{
Synthesis of Novel Benzimidazolium Gemini Surfactants and Evaluation of Their Anti-Candida Activity
}

\author{
Farooq Ahmad Wani, ${ }^{\dagger, \|}$ Amaduddin, ${ }^{\ddagger}$ Babita Aneja, ${ }^{\ddagger}$ Gerard Sheehan, ${ }^{\S}$ Kevin Kavanagh, ${ }^{\S}$
} Rabia Ahmad," Mohammad Abid,*,+(0) and Rajan Patel ${ }^{*}+$ (i)

\begin{abstract}
${ }^{\dagger}$ Biophysical Chemistry Laboratory, Centre for Interdisciplinary Research in Basic Sciences, Jamia Millia Islamia (A Central University), New Delhi 110025, India

${ }^{\ddagger}$ Medicinal Chemistry Laboratory, Department of Biosciences, and "Department of Chemistry, Jamia Millia Islamia, New Delhi 110025, India

${ }^{\S}$ Department of Biology, Maynooth University, Co Kildare 045, Ireland
\end{abstract}

Supporting Information

\begin{abstract}
Owing to the rise in antimicrobial and chemotherapeutic drug resistance, there is a desperate need to formulate newer as well as more effective agents. With this perspective, here we outline the synthesis of two novel gemini surfactants with different substitutions at the nitrogen atom of the benzimidazolium ring. Both the compounds induced significant reductions in Candida growth in various yeast strains. The reduction in Candida growth seemed likely through the reduction in ergosterol biosynthesis: a sterol constituent of yeast cell membranes. Different concentrations of both compounds were used to determine the cellular ergosterol content which indicates an important disordering of

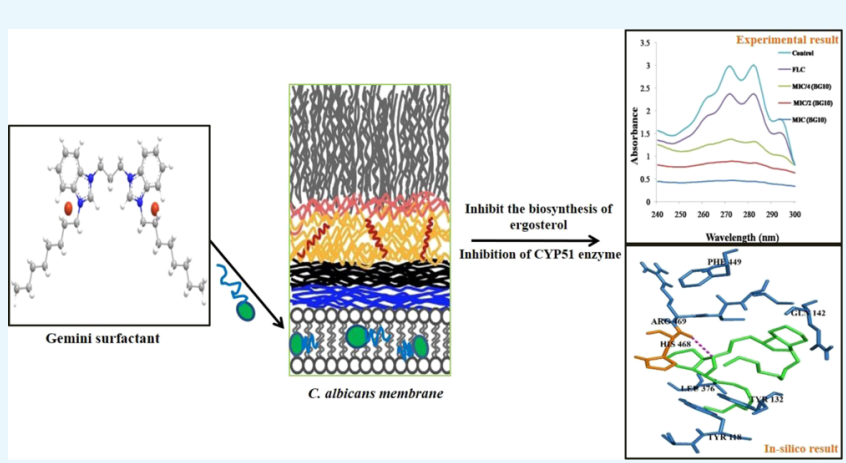
the ergosterol biosynthetic pathway. Cytotoxic studies were carried out using HEK 293 (human embryonic-kidney cells) and Galleria mellonella larvae (an in vivo model of antimicrobial studies). Administration of both the compounds to G. mellonella larvae diseased by the yeast Candida albicans resulted in increased survival indicating their in vivo activity.
\end{abstract}

\section{INTRODUCTION}

One of the serious problems people currently face in daily life is their inexorable exposure to several bacteria, fungi, and many other micro-organisms. The emergence of resistant microorganisms against available antimicrobial agents is a matter of serious concern. ${ }^{1}$ Persistent fungal infections are connected with higher death/mortality rates in immuno-compromised hosts, such as cancer patients, organ transplantation, and acquired immuno deficiency syndrome. ${ }^{2}$ The range of effective and safer antifungal agents is limited, despite thehigh death rate associated with fungal infections. ${ }^{3}$ Conventional antifungal agents, that is, fluconazole (FLC), caspofungin, and amphotericin B have some therapeutic limits like related drug toxicity, uneven bioavailability, and absence of oral/ intravenous preparations. More significantly, increasing resistance to the majority of the clinically used antifungal agents has considerably minimized the outcome rate of antifungal therapy leading to higher mortality. ${ }^{4}$ Thus, the identification of harmless and effective antifungal agents to gear up challenges of increasing frequency/incidences of fungal infections is immediately required. ${ }^{4,5}$ Gemini surfactants are novel surfactants which have drawn much attention from both academic and industrial research communities and possess effective antimicrobial activity. ${ }^{6,7}$ These are amphiphilic in nature having two hydrophilic moieties as well as two hydrophobic tails joined by a spacer who may be stiff or stretchy. ${ }^{8-10}$ Gemini surfactants have improved physicochemical features like lesser critical micelle concentration $(\mathrm{cmc})$, high efficiency of adsorption, better wetting and foaming ability, solubilizing power, as well as soap lime-dispersing properties, ${ }^{11-15}$ wetting agent, emulsifier, fabric softener, and foaming agents. ${ }^{16-19}$ Gemini surfactants are more efficient in reducing surface tension and form micelles comparatively at lower concentrations as compared to monomeric surfactants. $^{20,21}$

The surfactants with the quaternary ammonium head group have been extensively used as antimicrobial agents over the decades. ${ }^{22,23}$ These surfactants kill the microorganisms mostly because of electrostatic and hydrophobic interactions on the cell surfaces ${ }^{24}$ by intercalating the cell membrane and changing its molecular organization, which increases membrane permeability and thus results in cytoplasmic diffusion and

Received: April 13, 2019

Accepted: June 10, 2019

Published: July 9, 2019 
cell lysis. ${ }^{25}$ The cytotoxicity and green behavior of the gemini surfactants are of immense importance ahead of their use in any potential field. ${ }^{26-28}$ Although various reports are centered on their antimicrobial activities, ${ }^{29-31}$ the exact means of action is not yet completely understood. Consequently, the main aim of this study was to design and synthesize new gemini surfactants and evaluate their antifungal activity. Therefore, in this work, we have synthesized two novel benzimidazoliumbased gemini surfactants 1,3-bis(1,1-dialkyl benzimidazolium)propane bromide expressed as BG8 and BG10, respectively, and characterized by Fourier transform infrared (FT-IR), NMR, and mass spectroscopy (Scheme S1). The purity of these surfactants was checked by high performance liquid chromatography. The physicochemical characterization was also performed using tensiometry given in the Supporting Information. The anti-candida studies for these compounds against three strains of Candida (Candida albicans, Candida glabrata, and Candida tropicalis) along with one fluconazole (FLC) resistant $C$. albicans strain were performed. The following Scheme 1 shows the probable mechanism of action of gemini benzimidazolium surfactants with yeast membrane.

Scheme 1. Probable Mechanism of Action of Gemini Benzimidazolium Surfactants with a Yeast Membrane

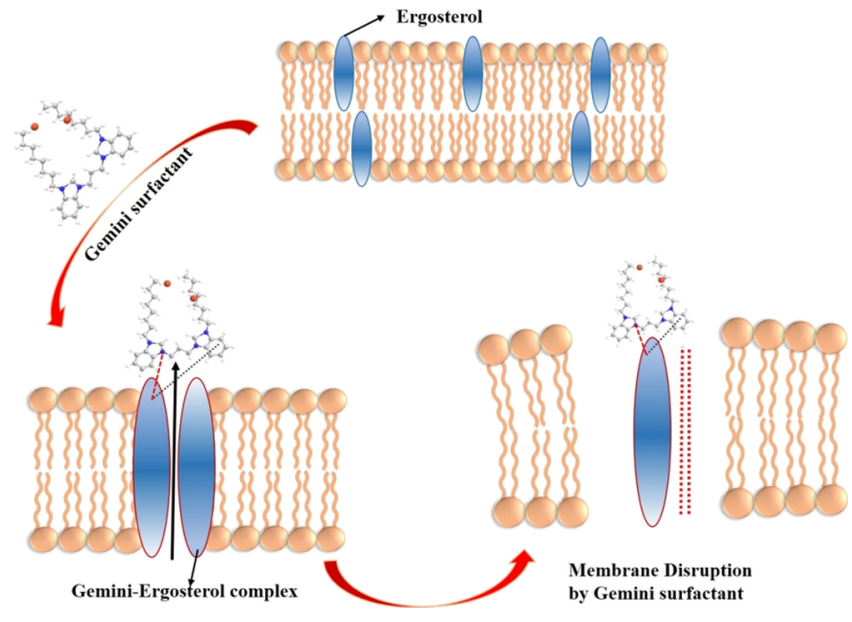

\section{RESULTS AND DISCUSSION}

2.1. Anti-candida Studies. 2.1.1. In Vitro Anti-candida Activity. The anti-candida studies for these compounds against three strains of Candida (C. albicans, C. glabrata, and $C$. tropicalis) along with one FLC resistant $C$. albicans strain were performed and the results suggested that gemini benzimidazolium surfactants showed better anti-candida potential as compared to the reference drug FLC. Both surfactants, BG8 and BG10 also exhibited potent inhibitory activity against the resistant strain with minimum inhibitory concentration (MIC) value of 23.7 and $10.9 \mu \mathrm{M}$, respectively, indicating that BG10 is more effective against the resistant $C$. albicans strain compared with standard drug FLC (Table 1). BG8 exhibited a MIC value of $23.7 \mu \mathrm{M}$ against all the three sensitive strains. Moreover, BG10 was observed to be more effective than that of BG8 and reference drug FLC $51 \mu \mathrm{M}$ against $C$. tropicalis strains with a value of MIC $10.9 \mu \mathrm{M}$, respectively. Because it is renowned that $C$. albicans is to blame for $50-60 \%$ cases of the pathological condition of fungus infection (candidiasis), ${ }^{30,32}$ we concentrate our studies on the $C$. albicans strain. Based on
Table 1. MIC Values (in $\mu \mathrm{M}$ ) of BG8 and BG10 against Different Strains of Candida ${ }^{a}$

\begin{tabular}{lccc}
\multicolumn{1}{c}{ strains } & BG8 & BG10 & FLC \\
C. albicans ATCC90028 & 23.7 & 21.8 & 51.0 \\
C. glabrata ATCC90030 & 23.7 & 10.9 & 25.5 \\
C. tropicalis ATCC750 & 23.7 & 10.9 & 51.0 \\
FLC-resistant C. albicans & 23.7 & 10.9 & 3265
\end{tabular}

${ }^{a}$ C. albicans resistant $=$ clinical isolates of C. albicans $($ FLC resistant $)$; FLC = fluconazole.

the results obtained with standard Candida strains, these surfactants were further investigated against FLC-resistant $C$. albicans. Similar results were also reported by Ruiz et al. ${ }^{32}$ They reported that green cationic gemini surfactants $N^{\alpha}, N^{\omega}$ bis $\left(N^{\alpha}\right.$,caproylarginine $) \alpha, \omega$-propyldiamide (C3(CA)2) and lichenysin exhibited antimicrobial synergies against $C$. albicans, Bacillus subtilis, Yersinia enterocolitica, and Escherichia coli, and observed that C3(CA)2-lichenysin exhibited lesser MIC values than the individual ones. Zhang et al. has also reported the antibacterial as well as antifungal activities of gemini surfactant monomers and copolymers with better MICs than the conventional surfactants. ${ }^{33}$

2.1.2. Growth Curve. To investigate the impact of those potent surfactants (BG8 and BG10) on the expansion of Candida cells, growth curve studies were performed. Completely different concentrations of the test compounds (2MIC, MIC, and MIC/2) were exposed on the Candida cells (Figure 1a,b). The positive and negative controls were taken as FLC-treated cells and untreated cells, respectively. The Candida cells do not show any noteworthy growth once exposed to MIC and 2MIC concentrations of these surfactants with the incessant lag stage of $24 \mathrm{~h}$. But, at sub-MIC concentrations of BG8 and BG10, growth has been found after 7 and $12 \mathrm{~h}$, respectively, for a standard C. albicans strain. In the case of the FLC-resistant Candida strain, growth has been observed after 10 and $14 \mathrm{~h}$ when exposed to sub-MIC concentrations of BG8 and BG10, respectively. Moreover, FLC exhibited less efficacy in inhibiting the growth of FLC-resistant Candida cells than BG8 and BG10. The above results reveal that BG10 was observed to be a good inhibitor against Candida cell growth as compared to BG8 as shown in Figure 1c,d.

2.1.3. Synergistic Study. The in vitro synergistic activity of anti-candida in grouping with FLC was also performed against standard and FLC-resistant C. albicans strains. The outcomes revealed that anti-candida activity of each surfactant BG8 and BG10 against the standard $C$. albicans strain was significantly improved when used in a mixture with FLC. The fractional inhibitory concentration index (FICI) values of surfactants BG8 and BG10 were 0.253 and 0.127 against the standard $C$. albicans strain indicating moderate synergy of BG8 and a highly synergistic effect of BG10 (Table 2). Moreover, BG10 also exhibited potential synergistic activity with a FICI value of 0.250 against the FLC-resistant $C$. albicans strain while BG8 also shows synergy in combination with FLC in the same strain (Tables 2 and 3). ${ }^{34,35}$

2.1.4. Ergosterol Biosynthesis in C. albicans. The effect of these compounds on ergosterol biosynthesis in C. albicans was examined in order to determine whether they affected cell membrane biosynthesis. The quantitative total sterol profiling in C. albicans ATCC 90028 was determined as described by an earlier stated method. ${ }^{36}$ FLC was taken as the positive control. The results clearly demonstrated a decrease in dose-dependent 

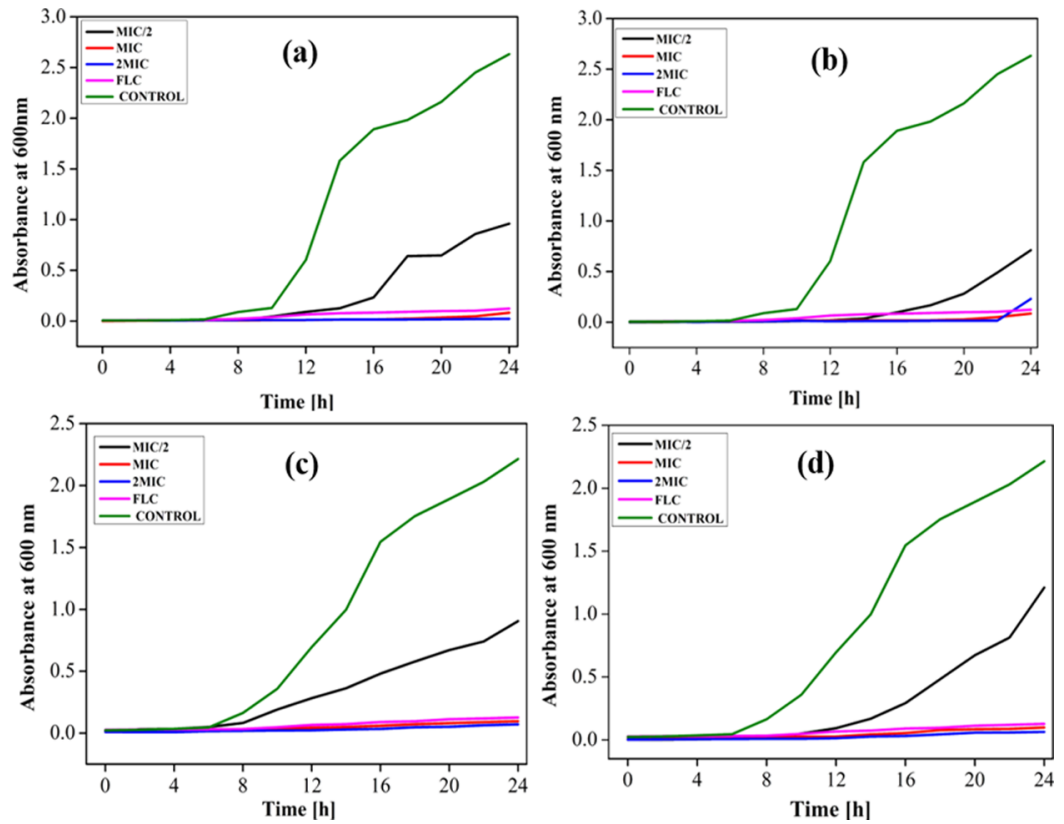

Figure 1. Dose-dependent growth curve of C. albicans ATCC-90028 in the presence of (a) BG8 and (b) BG10, FLC-resistant C. albicans D15.9 in the presence of (c) BG8 and (d) BG10.

Table 2. In Vitro Synergistic Anti-candida Activity of BG8

\begin{tabular}{|c|c|c|c|c|c|c|}
\hline \multirow[b]{2}{*}{ compound } & \multicolumn{2}{|c|}{$\begin{array}{l}\text { MIC alone } \\
(\mu \mathrm{M})\end{array}$} & \multicolumn{2}{|c|}{$\begin{array}{c}\text { MIC in } \\
\text { combination } \\
(\mu \mathrm{M})\end{array}$} & \multirow[b]{2}{*}{$\mathrm{FICI}^{a}$} & \multirow[b]{2}{*}{$\begin{array}{l}\text { mode of } \\
\text { interaction }\end{array}$} \\
\hline & BG8 & FLC & BG8 & FLC & & \\
\hline $\begin{array}{l}\text { C. albicans } \\
\text { (ATCC } \\
90028 \text { ) }\end{array}$ & 23.7 & 51.0 & 5.29 & 12.7 & 0.253 & synergy \\
\hline $\begin{array}{l}\text { C. albicans } \\
\text { D15. } 9^{a}\end{array}$ & 23.7 & 3265 & 11.86 & 816 & 0.250 & synergy \\
\hline
\end{tabular}

${ }^{a}$ FICI $=$ fractional inhibitory concentration index; synergy and antagonism were defined by FICI $\leq 0.5$ and $>4$, respectively. Indifference was defined by $0.5<\mathrm{FICI} \leq 4$.

Table 3. In Vitro Synergistic Anti-candida Activity of BG10

\begin{tabular}{|c|c|c|c|c|c|c|}
\hline \multirow[b]{2}{*}{ compound } & \multicolumn{2}{|c|}{$\begin{array}{l}\text { MIC alone } \\
\quad(\mu \mathrm{M})\end{array}$} & \multicolumn{2}{|c|}{$\begin{array}{l}\text { MIC in } \\
\text { combination } \\
(\mu \mathrm{M})\end{array}$} & \multirow[b]{2}{*}{$\mathrm{FICI}^{a}$} & \multirow[b]{2}{*}{$\begin{array}{c}\text { mode of } \\
\text { interaction }\end{array}$} \\
\hline & BG10 & FLC & BG10 & FLC & & \\
\hline $\begin{array}{l}\text { C. albicans } \\
\text { (ATCC } \\
\text { 90028) }\end{array}$ & 21.8 & 51.0 & 2.73 & 6.36 & 0.127 & synergy \\
\hline $\begin{array}{l}\text { C. albicans } \\
\text { D15.9 }\end{array}$ & 10.9 & 3265 & 1.36 & 816 & 0.250 & synergy \\
\hline
\end{tabular}

${ }^{a}$ FICI = fractional inhibitory concentration index; synergy and antagonism were defined by FICI $\leq 0.5$ and $>4$, respectively. Indifference was defined by $0.5<\mathrm{FICI} \leq 4$.

ergosterol content as cells were grown in variable concentrations of BG compounds. It can be inferred from the results that the exposure of cells to BG compounds with MIC and $\mathrm{MIC} / 2$ levels expressively inhibited ergosterol biosynthesis (Figure 2a,b). However, these compounds are comparatively less effective at low concentrations (MIC/4). Moreover, BG8 and BG10 inhibited the total ergosterol synthesis content more effectively than FLC at all the tested concentrations.
2.2. In Vivo Studies. 2.2.1. Toxicity of BG8 and BG10 Gemini Surfactants in Galleria mellonella Larvae. Further, to evaluate the in vivo toxicity of these compounds, larvae of Galleria mellonella were inoculated with $20 \mu \mathrm{L}$ of BG8 and BG10, and viability was assessed over $96 \mathrm{~h}$. At concentrations ranging from 3030 to $70 \mu \mathrm{M}$, these compounds were nontoxic in the G. mellonella larvae, yielding $100 \pm 0 \%$ viability after 96 h (Figure 3a,c).

2.2.2. Antifungal Efficacy of BG Compounds in the $G$. mellonella Larvae. To estimate the in vivo anti-candida efficiency of BG compounds, the G. mellonella larvae was infected by an inoculum of $C$. albicans $\left(5 \times 10^{5}\right.$ per $\left.20 \mu \mathrm{L}\right)$. One hour post infection, the larvae were administered with 20 $\mu \mathrm{L}$ of BG compounds $(3030-70 \mu \mathrm{M})$ or $20 \mu \mathrm{L}$ of dimethyl sulphoxide (DMSO) $(10 \% \mathrm{v} / \mathrm{v})$ control, and viability was assessed over $96 \mathrm{~h}$. BG8 at $76 \mu \mathrm{M}$ increased the viability of the G. mellonella larvae to $76.66 \pm 3.33 \%$ at $48 \mathrm{~h}$ and $53.00 \pm$ $3.33 \%$ compared to the respective DMSO-injected controls $(48 \mathrm{~h} ; 66.66 \pm 3.33 \%, 72 \mathrm{~h} ; 33.33 \pm 6.66 \%)$. BG8 at concentrations ranging from 70 to $3030 \mu \mathrm{M}$ significantly increased the viability of the $G$. mellonella larvae following with C. albicans infection. Concentrations of BG10 of 70-3030 $\mu \mathrm{M}$ significantly increased larval viability at $48 \mathrm{~h}(100 \pm 0 \%, p>$ $0.01)$. A concentration of $151 \mu \mathrm{M}$ increased larval viability at $72 \mathrm{~h}(76.66 \pm 3.33 \%, p>0.05)$, as compared to the relative DMSO control $(33.33 \pm 6.66 \%)$. BG10 was effective in blocking C. albicans-induced larval mortality at $48 \mathrm{~h}(100 \% \pm$ $0 \%, p>0.01)$ Figure $3 \mathrm{~b}, \mathrm{~d}$. The above outcomes indicate that administration of BG8 and BG10 to the larvae produced no adverse effects (e.g., melanisation) or death which is a good indication that they may be nontoxic in mammals. Administration of compounds to larvae infected with $C$. albicans resulted in increased survival, indicating in vivo activity. This has been reported previously with novel antimicrobial compounds $^{37,38}$ and a strong relationship among the in vivo activity of compounds in larvae and rats has previously been demonstrated. ${ }^{39}$ 

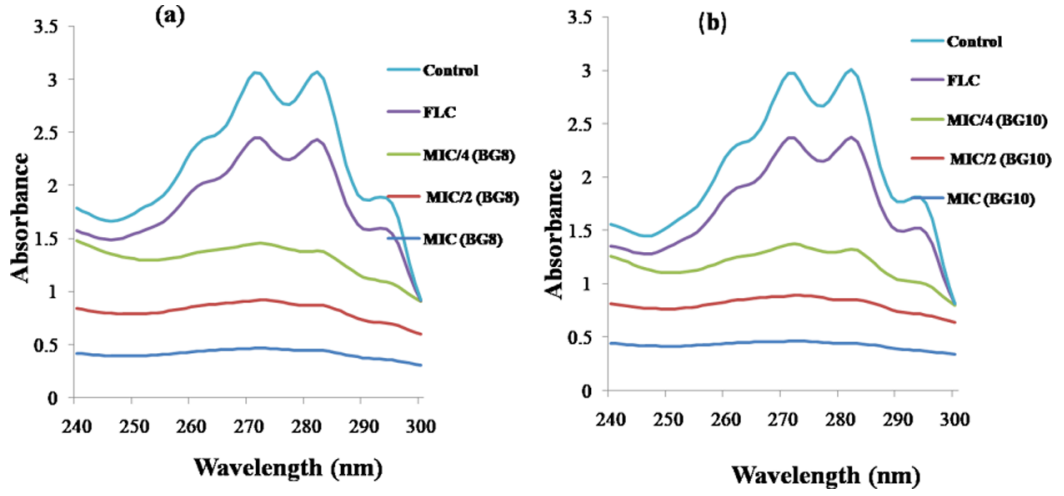

Figure 2. UV spectrophotometric sterol profiles of C. albicans ATCC-90028 after treatment with various concentrations (MIC/4, MIC/2, and MIC) of test compounds (a) BG8 and (b) BG10.
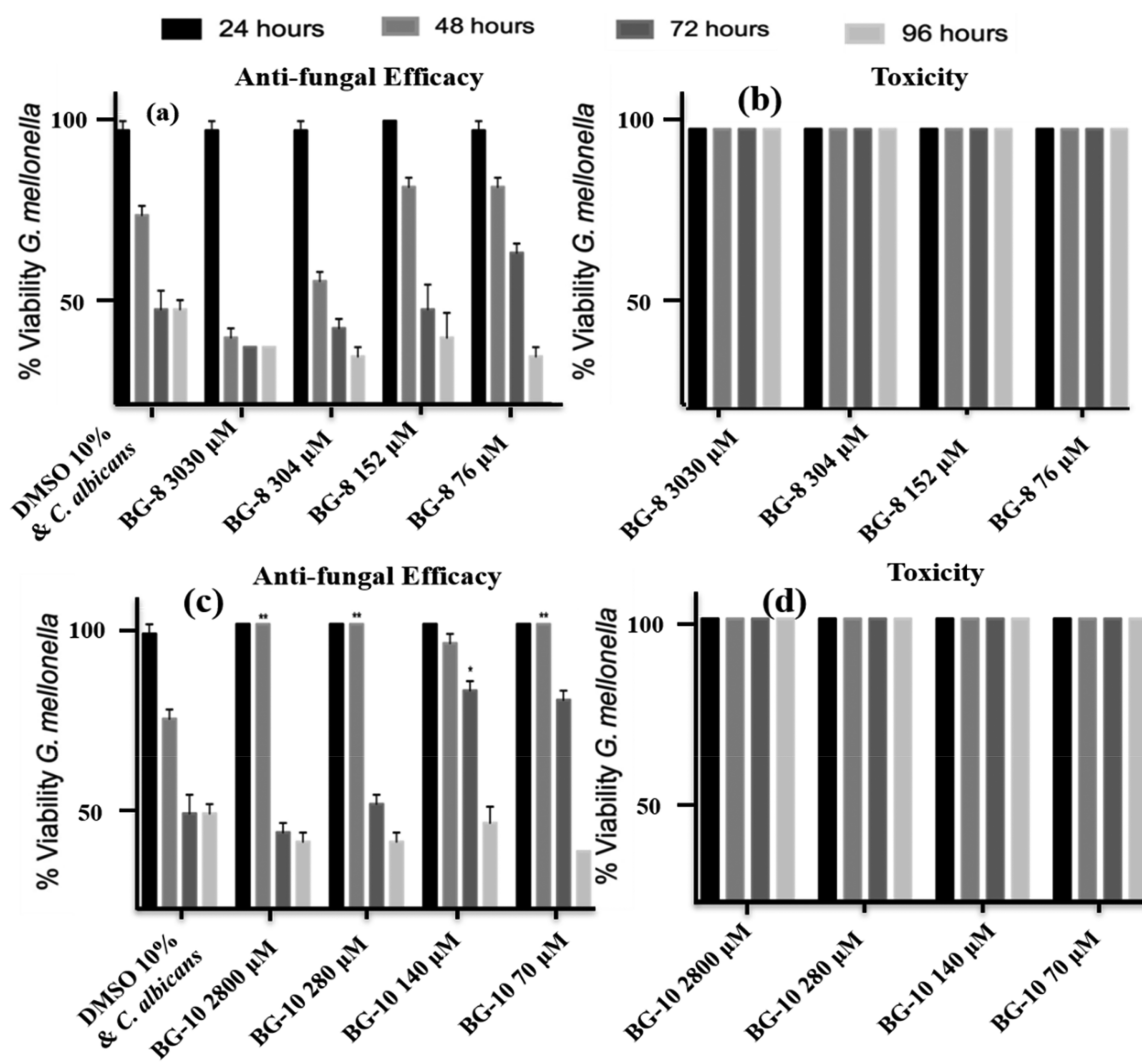

Toxicity

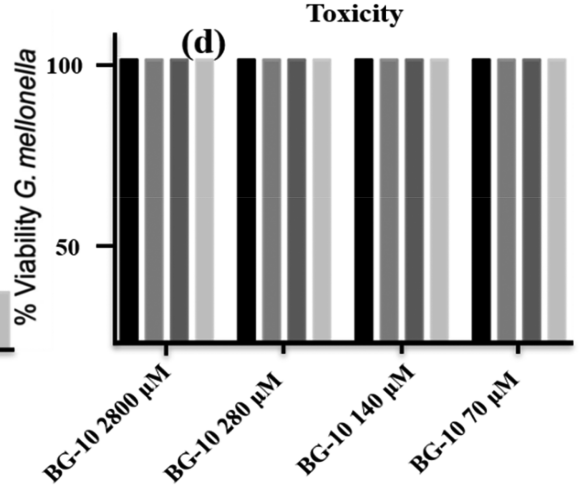

Treatments

Figure 3. Toxicity of BG8 (a) and BG10 (b) gemini surfactants in G. Mellonella larvae and antifungal efficacy of BG8 (c) and BG10 (d) gemini surfactants in G. Mellonella larvae.

2.3. In Silico Studies. The effect of these compounds on ergosterol biosynthesis was further confirmed by in silico studies in which both gemini surfactants were docked with an enzyme lanosterol 14- $\alpha$ demethylase (CYP51) member of the cytochrome P-450 super family that catalyzes the oxidative elimination of the 14- $\alpha$ alkyl group from lanosterol in the ergosterol biosynthesis pathway. The inhibition of CYP51 directly depleted ergosterol followed by the inhibition of yeast growth and acts as a primary target of azoles as antifungal drugs. The CYP51 crystal structure from pathogenic yeast $C$. albicans was recently published by the group of Keniya et al. and submitted to RCSB protein data bank (PDB ID: 5v5z). ${ }^{40}$ The interaction and binding energy of inhibitors BG8 and BG10 with CYP51 were identified using molecular docking
(Figure 4), and the docked results were compared with reference drug itraconazole. Both gemini surfactants contain the benzimidazolium group flanked by long alkyl hydrophobic side chains $\left(\mathrm{C}_{8} \mathrm{H}_{17}\right.$ in $\mathrm{BG} 8$ and $\mathrm{C}_{10} \mathrm{H}_{21}$ in BG10). The docking studies revealed that BG8 was bound close to the heme group in the active site of CYP51 interacting with active site residues such as Phe-449, Ile-471, Gln-142, Tyr-132, Leu-376, and forms a hydrogen bond with His-468 with a binding affinity of $-7.7 \mathrm{kcal} \mathrm{mol}^{-1}$. While as BG10 was bound to residues Tyr447, Phe-105, Glu-115, Arg-469, His-310, and a hydrogen bond with GLY-303 with a binding affinity of $-8.3 \mathrm{kcal} \mathrm{mol}^{-1}$ as compared to itraconazole shows $-9.6 \mathrm{kcal} \mathrm{mol}^{-1}$. ${ }^{41}$ Thus, the docking results support BG8, BG10 binding with the 14- $\alpha$ demethylase enzyme (CYP51) and inhibiting ergosterol 


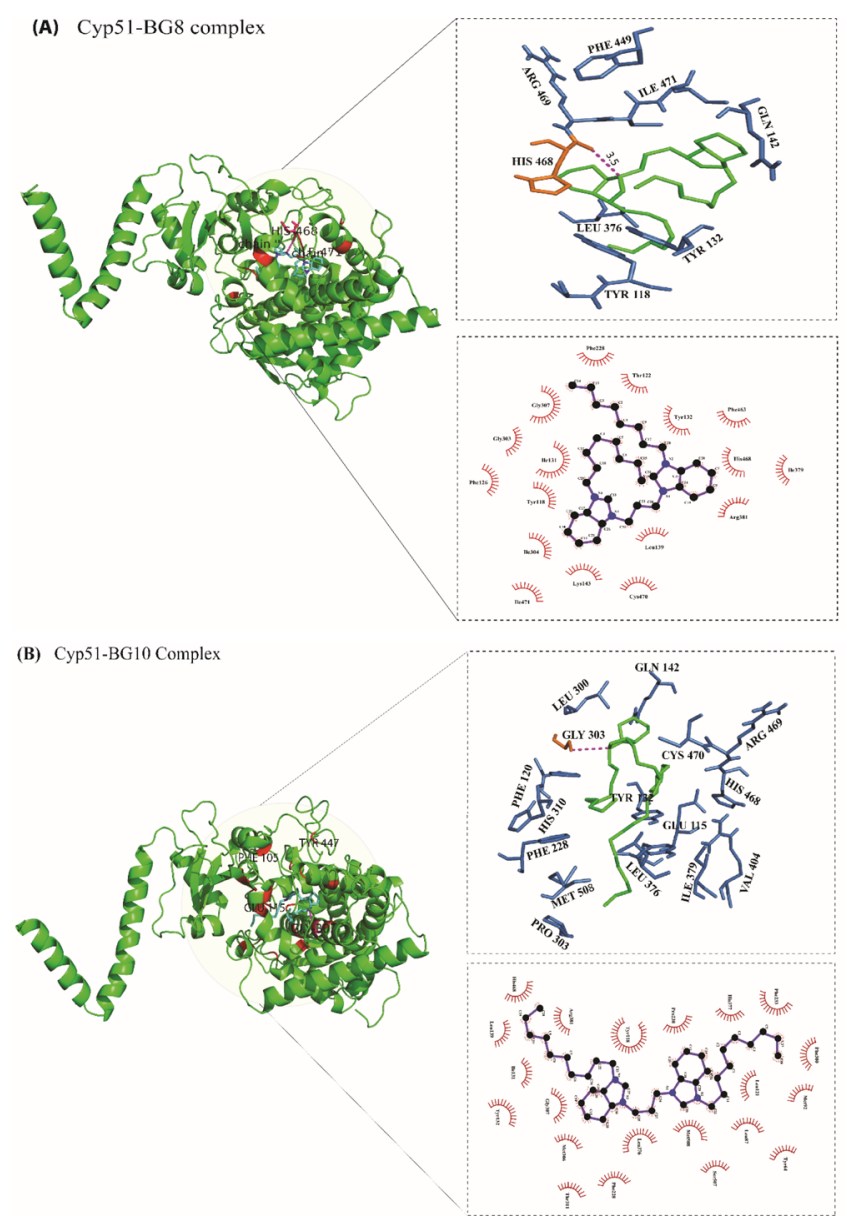

Figure 4. Cartoon model, 2D and ligplot of (A) CYP51-BG8 and (B) CYP51-BG10 complexes.

biosynthesis. The probable mechanism of action for gemini benzimidazolium surfactants with the yeast membrane is shown in Scheme 1.

2.4. Toxicity. 2.4.1. Hemolytic Assay. The toxicity of surfactants BG8 and BG10 on human red blood cells (hRBCs) were observed to evaluate the hemolytic assay. At $1510 \mu \mathrm{M}$ concentration, BG8 and BG10 showed reasonable toxicity triggering only 28 and $33 \%$ hemolysis, respectively, as compared to the reference drug FLC with $78 \%$ hemolysis. However, at $152 \mu \mathrm{M}$ concentration, these surfactants show low toxicity triggering only $13 \%$ (BG8) and 16\% (BG10) cell lysis. At $38 \mu \mathrm{M}$ concentration, BG8 and BG10 are totally harmless causing only 4 and $8 \%$ cell lysis, respectively. Thus, these potent anti-candida geminis exhibited less toxicity than the reference drug FLC at each tested concentration extending from 38 to $1510 \mu \mathrm{M}$ showing an extra protection index, as compared to reference drug FLC (Figure 5a).

2.4.2. Cytotoxicity Assay. The selected compounds were further evaluated for cytotoxicity by the (3-(4,5-dimethyl-2-yl)2,5-diphenyltetrazolium bromide) (MTT) assay on the noncancerous human cell line (HEK293), which is a specific cell line initially resulting from the cells of the human embryonic kidney grown by a tissue culture. HEK 293 cells are widely used in cell biological research over decades, because of their consistent growth and inclination for transfection. ${ }^{42-44}$ The selected compounds were screened in the concentration range of $0-160 \mu \mathrm{M}$, and it was found that even at $160 \mu \mathrm{M}$, compounds BG8 and BG10 do not disrupt the feasibility of

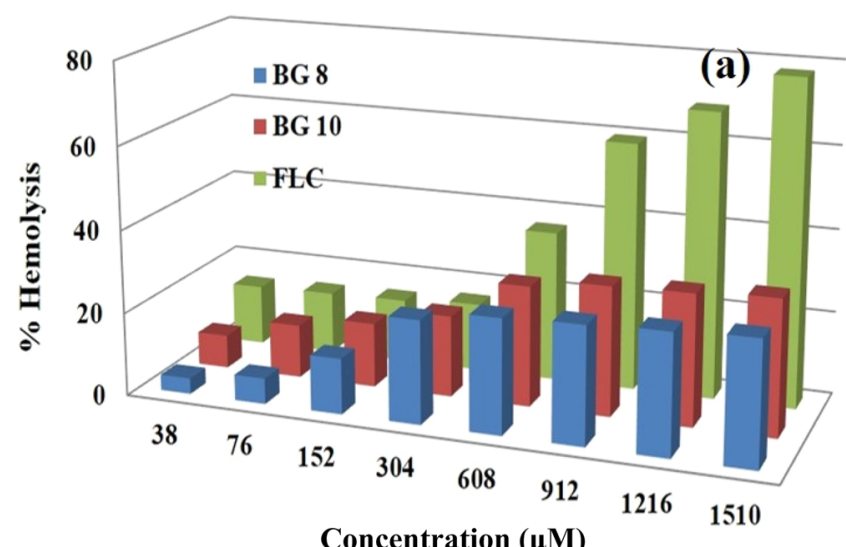

Concentration $(\mu \mathrm{M})$

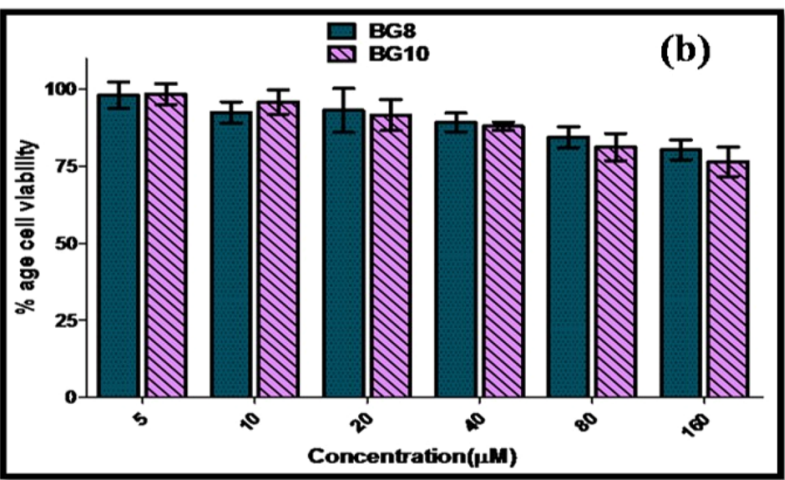

Figure 5. Hemolytic assays (a) and cell viability assay (b) of BG8 and BG10.

HEK293 in a significant manner. These results clearly advocated that the selected compounds are noncytotoxic to HEK293 cells in the tested concentration range. Further, these results speculate that these compounds might be used as potential antifungal molecules, as in the tested sub-micromolar concentration range, these exhibited a noncytotoxic nature towards normal human cells (Figure 5b).

\section{CONCLUSIONS}

Two benzimidazolium-based gemini surfactants BG8 and BG10 have been synthesized and were well characterized by FT-IR, ${ }^{1} \mathrm{H}$ NMR, ${ }^{13} \mathrm{C}$ NMR, and mass spectroscopy. Moreover, their physicochemical characterization was also done using a surface tension method to evaluate various interfacial parameters viz: $\Gamma_{\max }, p \mathrm{C}_{20}, A_{\min }$ and $P$ (packing parameter). The anti-candida studies for these compounds along with reference drug, FLC against three strains of Candida ( $C$. albicans, C. glabrata, and C. tropicalis) were performed and the results suggested that gemini BG surfactants showed better anti-candida potential as compared to the reference drug. BG8 and BG10 exhibit potent inhibitory activity against the resistant strain with MIC values of 23.7 and $10.9 \mu \mathrm{M}$, respectively, indicating that $\mathrm{BG} 10$ is more effective against the resistant $C$. albicans strain compared with standard drug FLC. Administration of these compounds to larvae infected with $C$. albicans resulted in increased survival indicating in vivo activity. The consequence of these compounds on ergosterol biosynthesis in C. albicans was examined to determine affected cell membrane biosynthesis and the results confirmed a decrease in dose-dependent ergosterol content once the cells had been grown in variable concentrations of test compounds. Our docking studies further confirmed the ergosterol biosynthesis 
Table 4. Surface Active Parameters of BG8 and BG10

\begin{tabular}{cccccccc} 
surfactants & $\mathrm{cmc}(\mathrm{mM})$ & $\gamma_{\mathrm{cmc}}\left(\mathrm{mN} \mathrm{m}^{-1}\right)$ & $\pi_{\mathrm{cmc}}\left(\mathrm{mN} \mathrm{m}^{-1}\right)$ & $p \mathrm{C}_{20}$ & $\Gamma_{\max }\left(10^{3} \mathrm{~mol} \mathrm{~m}^{-2}\right)$ & $A_{\min }\left(\mathrm{nm}^{2}\right)$ & 0.74 \\
BG8 & 13 & 35.75 & 39.6 & 1.57 & 2.22 & 0.45 \\
BG10 & 1.5 & 32.4 & 40.4 & 3.35 & 1.58 & 0.32 \\
\hline
\end{tabular}

in C. albicans, revealing that both BG8 and BG10 were bound close to the heme group in the active site of CYP51 with high binding affinities. The MTT assay with noncancerous human cell line (HEK293) results indicated that the selected compounds are noncytotoxic to the HEK293 cells in the tested concentration range.

\section{EXPERIMENTAL SECTION}

4.1. Materials. Benzimidazole (purity 99\% Sigma-Aldrich USA), 1-bromooctane, and 1-bromodecane (purity 99\% Sigma-Aldrich USA). The reagents were used without any extra purification. Milli-Q $\mathrm{H}_{2} \mathrm{O}$ with specific conductivity $<1.4$ $\mu \mathrm{S} \mathrm{cm}^{-1}$ was used throughout the experiments.

4.2. Synthesis. 1,3-Bis(1-octylbenzimidazolium)propane bromide $\left(\mathrm{C}_{34} \mathrm{H}_{53} \mathrm{Br}_{2} \mathrm{~N}_{4}\right)$ simply represented as $\mathrm{BG} 8$ and 1,3bis(1-decylbenzimidazolium) propane bromide $\left(\mathrm{C}_{38} \mathrm{H}_{63} \mathrm{Br}_{2} \mathrm{~N}_{4}\right)$ represented as BG10 were synthesized by the procedure given in the Supporting Information. The FT-IR, NMR and mass spectra were used to confirm the structures of all the products.

The spectral results of FT-IR, ${ }^{1} \mathrm{H} \mathrm{NMR},{ }^{13} \mathrm{CNMR}$, and mass are given below. (Figures $\mathrm{S} 1-\mathrm{S} 6$ )

4.2.1. BG8 Gemini 1,3-Bis(1-octylbenzimidazolium)propane Bromide $\left(\mathrm{C}_{34} \mathrm{H}_{53} \mathrm{Br}_{2} \mathrm{~N}_{4}\right)$. FT-IR $\left(4000-600 \mathrm{~cm}^{-1}\right.$ ATR tablet) $3050 \mathrm{~cm}^{-1}[v(\mathrm{Ar}-\mathrm{H})], 2915 \mathrm{~cm}^{-1}\left[v\left(\mathrm{CH}_{3}\right)\right]$, $2848 \mathrm{~cm}^{-1}\left[v\left(\mathrm{CH}_{2}\right)\right], 2031 \mathrm{~cm}^{-1}[v(\pi)]$ that is exocyclic $\mathrm{C}=$ C vibration, $1410 \mathrm{~cm}^{-1}[v(\mathrm{C}=\mathrm{N})], 1349 \mathrm{~cm}^{-1}[v(\mathrm{C}=\mathrm{C}$ bending $)], 1192 \mathrm{~cm}^{-1}[v(\mathrm{C}-\mathrm{C}$ bending $)], 888 \mathrm{~cm}^{-1}[v(\mathrm{C}-\mathrm{H}$ bending $)]$ and at $3324 \mathrm{~cm}^{-1}$ is due to the absorbed water.

${ }^{1} \mathrm{H}$ NMR $\left(\mathrm{CDCl}_{3}-\delta=7.5 \mathrm{ppm}\right) \delta=0.75 \mathrm{ppm}(\mathrm{t}, 6 \mathrm{H}), 1.25$ $(\mathrm{s}, 4 \mathrm{H}), 1.6(\mathrm{~m}, 16 \mathrm{H}), 3.6(\mathrm{q}, 4 \mathrm{H}), 4.5(\mathrm{t}, 4 \mathrm{H}), 5.8(\mathrm{~d}, 4 \mathrm{H})$, $7.8(\mathrm{~m}, 4 \mathrm{H}), 9.2(\mathrm{~d}, 4 \mathrm{H}), 10.2(\mathrm{~s}, 2 \mathrm{H}), 10.9(\mathrm{t}, 4 \mathrm{H})$.

${ }^{13} \mathrm{C} \mathrm{NMR}\left(\mathrm{CDCl}_{3}-\delta=80 \mathrm{ppm}\right) \delta=13.94 \mathrm{ppm}\left(\mathrm{CH}_{3}\right), 22.4$ $\left(\mathrm{CH}_{2}\right), 28.90\left(\mathrm{CH}_{2}\right), 30.10\left(\mathrm{CH}_{2}\right), 32.0\left(\mathrm{CH}_{2}\right), 50\left(\mathrm{CH}_{2}\right)$, $115.9(\mathrm{CH}), 127.2$ ( $\mathrm{C}$ attached at the bridged position), 131.2 ( $\mathrm{CH}$ of the six-membered ring), $139.9\left(\mathrm{CH}_{2}\right), 140(\mathrm{CH}=)$.

ESI-MS (LCMS): $\mathrm{C}_{33} \mathrm{H}_{50} \mathrm{~N}_{4} \mathrm{Br}_{2}$ found 649, calcd 660; $\mathrm{C}_{26} \mathrm{H}_{35} \mathrm{~N}_{4} \mathrm{Br}_{2}$ 539, calcd 557; $\mathrm{C}_{7} \mathrm{H}_{15}$ 112, calcd 99.

4.2.2. BG10 Gemini 1,3-Bis(1-decylbenzimidazolium)propane Bromide $\left(\mathrm{C}_{38} \mathrm{H}_{63} \mathrm{Br}_{2} \mathrm{~N}_{4}\right)$. FT-IR $\left(4000-600 \mathrm{~cm}^{-1}\right.$ ATR tablet) $3022 \mathrm{~cm}^{-1}[v(\mathrm{Ar}-\mathrm{H})] 2922 \mathrm{~cm}^{-1}\left[v\left(\mathrm{CH}_{3}\right)\right] 2853$ $\mathrm{cm}^{-1}\left[v\left(\mathrm{CH}_{2}\right)\right] 1870 \mathrm{~cm}^{-1}[v(\pi)]$ that is exocyclic $\mathrm{C}=\mathrm{C}$ vibration, $1559 \mathrm{~cm}^{-1}[v(\mathrm{C}=\mathrm{N})], 1452 \mathrm{~cm}^{-1}[v(\mathrm{C}=\mathrm{C}$ bending $)], 1209 \mathrm{~cm}^{-1}[v(\mathrm{C}-\mathrm{C}$ bending $)], 752 \mathrm{~cm}^{-1}[v(\mathrm{C}-$ $\mathrm{H}$ bending)] and 3401 and $1616 \mathrm{~cm}^{-1}$ is due to the $\mathrm{O}-\mathrm{H}$ stretching and bending of absorbed water.

${ }^{1} \mathrm{H}$ NMR $\left(\mathrm{CDCl}_{3}-\delta=7.5 \mathrm{ppm}\right) \delta=0.75 \mathrm{ppm}(\mathrm{t}, 6 \mathrm{H}), 1.5$ $(\mathrm{m}, 4 \mathrm{H}), 2.0(\mathrm{~m}, 20 \mathrm{H}), 3.6(\mathrm{q}, 4 \mathrm{H}), 4.5(\mathrm{t}, 4 \mathrm{H}), 5.2(\mathrm{~s}, 2 \mathrm{H})$, 7.5 (q, 4H), $8.6(\mathrm{~d}, 2 \mathrm{H}), 10.2(\mathrm{~d}, 2 \mathrm{H}), 10.75(\mathrm{t}, 4 \mathrm{H})$.

${ }^{13} \mathrm{C} \mathrm{NMR}\left(\mathrm{CDCl}_{3}-\delta=80 \mathrm{ppm}\right) \delta=13.97 \mathrm{ppm}\left(\mathrm{CH}_{3}\right)$, $22.51\left(\mathrm{CH}_{2}\right), 29.23\left(\mathrm{CH}_{2}\right), 30.1\left(\mathrm{CH}_{2}\right), 45.73\left(\mathrm{CH}_{2}\right), 47.83$ $\left(\mathrm{CH}_{2}\right), 114.79\left(\mathrm{CH}_{2}\right.$ attached to positively charged nitrogen $)$, $115.28(\mathrm{CH}), 127.6(\mathrm{CH}), 130.82(\mathrm{C}$ attached at the bridged position), $141.52(\mathrm{CH}=)$.

ESI-MS (LCMS): $\mathrm{C}_{37} \mathrm{H}_{58} \mathrm{~N}_{4} \mathrm{Br}_{2}$ found 721, calcd 718; $\mathrm{C}_{28} \mathrm{H}_{39} \mathrm{~N}_{4} \mathrm{Br}_{2}$ 557, calcd 585; $\mathrm{C}_{7} \mathrm{H}_{15}$ 110, calcd 110.7 .

4.3. Physicochemical Characterization. The physicochemical characterization of two newly synthesized gemini surfactants was done by using surface tensiometry (more details are given in the Supporting Information). The different interfacial parameters viz cmc, $\pi_{\mathrm{cmc}}, p \mathrm{C}_{20}, \Gamma_{\max }, A_{\min }$ and $P$ were evaluated by using different equations and are given in Table $4{ }^{10,16,17}$ In addition, the cmc values were also confirmed by UV-visible and pyrene probe fluorescence spectroscopy and given in the Supporting Information (Figure S9).

4.4. In Vitro Anti-candida Activity. Both the surfactants, BG8 and BG10 were investigated for their in vitro anti-candida activity against C. albicans (ATCC 90028), C. glabrata (ATCC 90030), C. tropicalis (ATCC 750), and FLC resistant C. albicans D15.9 strains by using the broth dilution procedure according to the quality protocol for antifungal assessment by NCCLS (National Committee for Clinical Laboratory Standards $).{ }^{45}$ FLC $(3.26 \mu \mathrm{M})$ was used as a positive control for the anti-candida study. The surfactant solutions were made in DMSO and diluted serially in a broth medium to attain the desired concentration of DMSO less than 1\%. Variable concentrations of surfactants $(1500-10.9 \mu \mathrm{M})$ were distributed into a 96 well plate in a Sabouraud dextrose (SD) broth medium in a $100 \mu \mathrm{L}$ final volume. Further, $100 \mu \mathrm{L}$ of yeast cells (approximate $2.5 \times 10^{3}$ cells $/ \mathrm{mL}$ using (McFarland standard ${ }^{45}$ were distributed into the 96 well plate (Tarson) with incubation at $37^{\circ} \mathrm{C}$ for $24 \mathrm{~h}$. During the incubated period each well was investigated for the attendance or absence of visual growth of yeast cells. The lowermost concentration of the tested compound on which no observable growth occurs characterizes its MIC value. Moreover, the growth was observed turbidometrically at $600 \mathrm{~nm}$ using a ThermoMultiskan Go spectrophotometer after incubation.

4.5. Growth Curve Studies. The cells of C. albicans were revived freshly by a subculture on a SD agar plate. A loopful of inoculum was introduced into the SD broth, finally the cells were grown for $16 \mathrm{~h}$ at $37^{\circ} \mathrm{C}$ before use. About $2 \times 10^{3}$ cells/ $\mathrm{mL}$ were injected into the freshly prepared $50 \mathrm{~mL}$ sterile $\mathrm{SD}$ medium. Various concentrations equal to $\mathrm{MIC}, \mathrm{MIC} / 2$, and $2 \mathrm{MIC}$ of the surfactants were separately added into the conical flasks comprising of the inoculated medium, which was incubated at $37^{\circ} \mathrm{C}$ and $160 \mathrm{rpm}$. Strain specific concentration of FLC was used as positive control of $102 \mu \mathrm{M}$ for C. albicans ATCC90028 and $3260 \mu \mathrm{M}$ C. albicans D15.9 (FLC resistant), respectively. At prearranged time periods $(0,2,4,6,8,10,12$, $14,16,18,20,22$, and 24 after incubation with agitation at 37 ${ }^{\circ} \mathrm{C}$ ), $1 \mathrm{~mL}$ aliquot from each sample in a conical flask was removed and growth was observed turbidometrically at 600 nm using a Thermo Multiskan spectrophotometer. The optical densities were recorded against each concentration with time (hour).

4.6. FIC Index/Synergistic Activity. The fractional inhibitory concentration (FIC) index or synergistic activity of BG8 and BG10 with FLC was determined against C. albicans. Synergy and antagonism were defined by FIC indices of $<0.5$ and $>4$, respectively. The FIC index result of $>0.5$, but $<4$ was considered indifferent. Both surfactants BG8 and BG10 were serially diluted in growth medium with concentration ranging from 95 to $0.04 \mu \mathrm{M}$ against $C$. albicans ATCC90028 and $62.5-0.03 \mu \mathrm{M}$ of FLC, respectively. The 
MIC values of compound alone and in combination with FLC were determined by broth micro dilution method in 96 well plate. FIC index was calculated by using the following eq $1^{41}$

$$
\begin{aligned}
& \text { FIC }= \frac{\text { MIC of drug A in combination with B }}{\text { MIC of drug A alone }} \\
&+\frac{\text { MIC of drug B in combination with A }}{\text { MIC of drug B alone }}
\end{aligned}
$$

4.7. Ergosterol Biosynthesis in C. albicans. The whole intracellular sterols were estimated as reported earlier using standard C. albicans ATCC 90028. Three distinct conical flasks containing compounds BG8 and BG10 at MIC, MIC/2, and MIC/4 in the SD broth injected with freshly cultured cells of C. albicans ATCC 90028 were used. FLC $(130 \mu \mathrm{M})$ was taken as the positive control and untreated cells were taken as the negative control for comparison and conical flasks were incubated at $35{ }^{\circ} \mathrm{C}$ for $16 \mathrm{~h}$. The cells were harvested at their stationary phase after incubation and the weight of the pellet was determined. The pellet was treated with $\mathrm{KOH}$ solution (25\% alcoholic potassium hydroxide) followed by incubation at $85{ }^{\circ} \mathrm{C}$ for $1 \mathrm{~h}$. After incubation, sterol was removed by the addition of $n$-heptane/distilled water (1:3 ratio). The layers of heptane were moved into the fresh test tubes diluted five-fold in $100 \%$ ethanol and observed spectrophotometrically in the range of $240-300 \mathrm{~nm}$. The existence of ergosterol and late-sterol intermediate DHE in the extracted samples shows a characteristic four peak curve. ${ }^{46,47}$

4.8. Assessment of Anti-candida Compound Toxicity and Efficacy in G. mellonella. Sixth instar larvae of the G. mellonella greater wax: moth (Live foods Direct Ltd. Sheffield, England) were kept in the dark at $15{ }^{\circ} \mathrm{C}$ to avoid pupation. Larvae which weigh $0.22 \pm 0.03 \mathrm{~g}$ were selected and used within 2 weeks of receiving. 10 healthy larvae per treatment and controls $(n=3)$ were positioned in sterile $9 \mathrm{~cm}$ Petri dishes creased with Whatman filter paper with some wood shavings. Larvae were adjusted to $30^{\circ} \mathrm{C}$ for $1 \mathrm{~h}$ prior to all experiments and incubated at $30{ }^{\circ} \mathrm{C}$ for all studies. All experiments were done independently at three distinct times. For toxicity studies, larvae were injected with $20 \mu \mathrm{L}$ of BG8 and BG10 $(3030-76 \mu \mathrm{M})$ by last left pro-leg, and reaction to stimuli was measured every $24 \mathrm{~h}$. To assess the antifungal efficacy of BG8 and BG10 a culture of Candida albicans were grown to the immobile phase (nearly $2 \times 10^{8} / \mathrm{mL}$ ) in the YEPD broth $(2 \% \mathrm{w} / \mathrm{v}$ glucose, $2 \% \mathrm{w} / \mathrm{v}$ bactopptone, $1 \% \mathrm{w} / \mathrm{v}$ yeast extract) at $30{ }^{\circ} \mathrm{C}$ and $200 \mathrm{rpm}$. By centrifugation, (2056g for $5 \mathrm{~min}$ ) the cells were harvested by using a GS-6 Beckmann bench-centrifuge and washed in phosphate-buffered saline (PBS) three times and resuspended again in PBS at $5 \times 10^{5} / 20$ $\mu \mathrm{L}$. The larvae were injected with yeast cells via the last left pro-leg into the hemocoel with a Myjector U-100 insulin syringe (Terumo. Europe. N.V., Belgium) and positioned at 30 ${ }^{\circ} \mathrm{C}$ in the dark. One hour post injection, larvae were injected with compounds BG8 and BG10 at varying concentrations resuspended in PBS added with 10\% DMSO (v/v) through the last right pro-leg. Infected larvae were injected with $20 \mu \mathrm{L}$ PBS supplemented with $10 \%$ DMSO (v/v). To assess larval viability, larvae which did not respond to touch stimulus were considered dead.

4.9. Hemolytic Assay. The haemolytic activity of the surfactants BG8 and BG10 and the conventional antifungal drug FLC were determined on human red blood cells (hRBCs). Human erythrocytes from healthy individuals were collected in tubes containing EDTA as an anticoagulant. The erythrocytes were harvested by centrifugation for $10 \mathrm{~min}$ at $2000 \mathrm{rpm}$ and $20^{\circ} \mathrm{C}$, and washed three times in phosphate buffered saline (PBS). To the pellet, PBS was added to yield a $10 \%(\mathrm{v} / \mathrm{v})$ erythrocytes/PBS suspension. The $10 \%$ suspension of erythrocytes was then further diluted with PBS at a 1:10 ratio. $100 \mu \mathrm{L}$ of the final diluted erythrocytes was added to 100 $\mu \mathrm{L}$ of PBS having a previously determined concentration gradient $(38 \mu \mathrm{M}$ to $1.51 \mathrm{mM}$ ) of the test compounds in microcentrifuge tubes. Total hemolysis was attained in $1 \%$ Triton X-100. The tubes were incubated for $1 \mathrm{~h}$ at $37^{\circ} \mathrm{C}$ and then centrifuged for $10 \mathrm{~min}$ at $2000 \mathrm{rpm}$ at room temperature. From the supernatant fluid, $150 \mu \mathrm{L}$ was transferred to a flat bottomed microtiter plate (Tarson), and the absorbance was measured spectrophotometrically at $450 \mathrm{~nm}$ by using a Thermo Multiskan spectrophotometer. The hemolysis percentage was calculated by following eq $2^{36}$

$$
\% \text { hemolysis }=\left[\begin{array}{l}
\left(\begin{array}{l}
A_{450} \text { of test compound treated sample }-A_{450} \\
\text { of buffer treated sample })
\end{array}\right. \\
\begin{array}{l}
\left(A_{450} \text { of } 1 \% \text { Triton X-100 treated sample }-A_{450}\right. \\
\text { of buffer treated sample })
\end{array}
\end{array}\right]
$$

$\times 100 \%$

4.10. Cytotoxicity by MTT Assay. HEK293 cell lines were procured from the National Centre for Cell Sciences (NCCS) Pune, India. Dulbecco's modified Eagle's medium (DMEM), antibiotic cocktail, and fetal bovine serum (FBS) were procured from Gibco Life Technologies. Thermo Fisher Scientific (USA). MTT and trypsin-EDTA solution has been purchased from Sigma (St. Louis, MO). HEK293 cells has been cultured and maintained in DMEM media enriched with $10 \%$ heat inactivated FBS and $1 \%$ penicillin, streptomycin solution at $37{ }^{\circ} \mathrm{C}$ in a humidified atmosphere of $5 \% \mathrm{CO}_{2}$. Cell cultures have been routinely preserved and trypsinized not beyond 30 passages. HEK293 cells were broadcasted in triplicate in 96-well plate containing a cell count of approximately 9000-10000 cells/well and incubated in a $\mathrm{CO}_{2}$ incubator for $24 \mathrm{~h}$. Then, the cells were incubated with increasing concentrations of test compounds $(5-250 \mu \mathrm{M})$ in a final volume of $200 \mu \mathrm{L}$ for $48 \mathrm{~h}$ at $37{ }^{\circ} \mathrm{C}$ in a $\mathrm{CO}_{2}$ incubator. The mixture of the culture medium and compounds were removed after $48 \mathrm{~h}$ of incubation at $37^{\circ} \mathrm{C}$ and cells have been washed two times with a PBS ( $\mathrm{pH} 7.4)$ solution. After that, freshly prepared $20 \mu \mathrm{L} \mathrm{MTT}$ at a concentration of $48.27 \mathrm{mM}$ in PBS and $100 \mu \mathrm{L}$ of DMEM has been added to each well and the plates were incubated for $4-5 \mathrm{~h}$ at $37{ }^{\circ} \mathrm{C}$ in the $\mathrm{CO}_{2}$ incubator. DMSO $(150 \mu \mathrm{L} /$ well $)$ was added to solubilize the formazan crystals, the metabolized MTT product, and was allowed a short incubation of $10 \mathrm{~min}$ at $27^{\circ} \mathrm{C}$. The absorbance was noted at $570 \mathrm{~nm}$ on the multi-plate ELISA reader (BioRad, USA). \% viability was taken as the comparative absorbance of treated versus untreated control cells and plotted as a function of concentration of compounds. All the results were obtained in triplicate.

4.11. Statistical Analysis. The data were evaluated as oneway analysis of variance (AVOVA) to detect the mean values observed for control and after treatment with compounds. Dunnett's test was used to compare the treatment, control and statistical significance was set at $P \leq 0.01$. 


\section{ASSOCIATED CONTENT}

\section{S Supporting Information}

The Supporting Information is available free of charge on the ACS Publications website at DOI: 10.1021/acsomega.9b01056.

Experimental protocol of physicochemical characterization and docking studies (PDF)

\section{AUTHOR INFORMATION}

\section{Corresponding Authors}

*E-mail: mabid@jmi.ac.in (M.A.).

*E-mail: rpatel@jmi.ac.in. Phone: +91 8860634100. Fax: +91 1126983409 (R.P.).

\section{ORCID $\odot$}

Mohammad Abid: 0000-0002-0507-8451

Rajan Patel: 0000-0002-3811-2898

\section{Notes}

The authors declare no competing financial interest.

\section{ACKNOWLEDGMENTS}

R.P. thanks the Science and Engineering Research Board (SERB), New Delhi for providing research grant with Sanction order nos. (SB/EMEQ-097/2013 and EEQ/2016/000339). The authors also thank DST for providing the FIST grant with Sanction order no. (SR/FIST/LS-541/2012).

\section{REFERENCES}

(1) Samosorn, S.; Tanwirat, B.; Muhamad, N.; Casadei, G.; Tomkiewicz, D.; Lewis, K.; Suksamrarn, A.; Prammananan, T.; Gornall, K. C.; Beck, J. L.; Bremner, J. B. Antibacterial activity of berberine-NorA pump inhibitor hybrids with a methylene ether linking group. Bioorg. Med. Chem. 2009, 17, 3866-3872.

(2) Brown, G. D.; Denning, D. W.; Levitz, S. M. Tackling Human Fungal Infections; American Association for the Advancement of Science, 2012.

(3) Lai, C.-C.; Tan, C.-K.; Huang, Y.-T.; Shao, P.-L.; Hsueh, P.-R. Current challenges in the management of invasive fungal infections. $J$. Infect. Chemother. 2008, 14, 77.

(4) Pfaller, M. A.; Diekema, D. J.; Rinaldi, M. G.; Barnes, R.; Hu, B.; Veselov, A. V.; Tiraboschi, N.; Nagy, E.; Gibbs, D. L. Results from the ARTEMIS DISK Global Antifungal Surveillance Study: a 6.5-year analysis of susceptibilities of Candida and other yeast species to fluconazole and voriconazole by standardized disk diffusion testing. J. Clin. Microbiol. 2005, 43, 5848-5859.

(5) Paiva, J. A.; Pereira, J. M. New antifungal antibiotics. Curr. Opin. Infect. Dis. 2013, 26, 168-174.

(6) Patel, R.; Mir, M. U. H.; Maurya, J. K.; Singh, U. K.; Maurya, N.; Parray, M. u. d.; Khan, A. B.; Ali, A. Spectroscopic and molecular modelling analysis of the interaction between ethane-1,2-diyl bis(N,N-dimethyl-N-hexadecylammoniumacetoxy)dichloride and bovine serum albumin. Luminescence 2015, 30, 1233-1241.

(7) Sharma, T.; Dohare, N.; Kumari, M.; Singh, U. K.; Khan, A. B.; Borse, M. S.; Patel, R. Comparative effect of cationic gemini surfactant and its monomeric counterpart on the conformational stability and activity of lysozyme. RSC Adv. 2017, 7, 16763-16776.

(8) Bhadani, A.; Singh, S. Synthesis and properties of thioether spacer containing gemini imidazolium surfactants. Langmuir 2011, 27, 14033-14044.

(9) Menger, F. M.; Keiper, J. S. Gemini surfactants. Angew. Chem., Int. Ed. 2000, 39, 1906-1920.

(10) Patel, R.; Khan, A. B.; Dohare, N.; Maroof Ali, M.; Rajor, H. K. Mixed micellization and interfacial properties of ionic liquid-type imidazolium gemini surfactant with amphiphilic drug amitriptyline hydrochloride and its thermodynamics. J. Surfactants Deterg. 2015, 18, 719-728.
(11) Leclercq, L.; Noujeim, N.; Schmitzer, A. R. Development ofN,N'-Diaromatic Diimidazolium Cations: Arene Interactions for Highly Organized Crystalline Materials. Cryst. Growth Des. 2009, 9, 4784-4792.

(12) Kim, S. S.; Zhang, W.; Pinnavaia, T. J. Ultrastable mesostructured silica vesicles. Science 1998, 282, 1302-1305.

(13) Tieke, B. Polymerisation of styrene in microemulsion with catanionic surfactant mixtures. Colloid Polym. Sci. 2005, 283, 421430

(14) Zana, R. Dimeric and oligomeric surfactants. Behavior at interfaces and in aqueous solution: a review. Adv. Colloid Interface Sci. 2002, 97, 205-253.

(15) Kamboj, R.; Singh, S.; Bhadani, A.; Kataria, H.; Kaur, G. Gemini imidazolium surfactants: synthesis and their biophysiochemical study. Langmuir 2012, 28, 11969-11978.

(16) Maurya, J. K.; Mir, M. U. H.; Singh, U. K.; Maurya, N.; Dohare, N.; Patel, S.; Ali, A.; Patel, R. Molecular investigation of the interaction between ionic liquid type gemini surfactant and lysozyme: A spectroscopic and computational approach. Biopolymers 2015, 103, $406-415$.

(17) Wani, F. A.; Khan, A. B.; Alshehri, A. A.; Malik, M. A.; Ahmad, R.; Patel, R. Synthesis, characterization and mixed micellization study of benzene sulphonate based gemini surfactant with sodium dodecyl sulphate. J. Mol. Liq. 2019, 285, 270-278.

(18) Patel, R.; Mir, M. U. H.; Singh, U. K.; Beg, I.; Islam, A.; Khan, A. B. Refolding of urea denatured cytochrome $\mathrm{c}$ : Role of hydrophobic tail of the cationic gemini surfactants. J. Colloid Interface Sci. 2016, 484, 205-212.

(19) ud din Parray, M.; Maurya, N.; Wani, F.; Ahmad Wani, M. S.; Arfin, N.; Ahmad Malik, M.; Patel, R. Comparative effect of cationic gemini surfactant and its monomeric counterpart on the conformational stability of phospholipase A2. J. Mol. Struct. 2019, 1175, 49-55.

(20) Matsuoka, K.; Chiba, N.; Yoshimura, T.; Takeuchi, E. Effect of double quaternary ammonium groups on micelle formation of partially fluorinated surfactant. J. Colloid Interface Sci. 2011, 356, 624-629.

(21) Pei, X.; Zhao, J.; Wei, X. Wormlike micelles formed by mixed cationic and anionic gemini surfactants in aqueous solution. J. Colloid Interface Sci. 2011, 356, 176-181.

(22) Martins, L. M. S.; Mamizuka, E. M.; Carmona-Ribeiro, A. M. Cationic vesicles as bactericides. Langmuir 1997, 13, 5583-5587.

(23) Wong, Y.-L.; Hubieki, M. P.; Curfman, C. L.; Doncel, G. F.; Dudding, T. C.; Savle, P. S.; Gandour, R. D. A structure-activity study of spermicidal and anti-HIV properties of hydroxylated cationic surfactants. Bioorg. Med. Chem. 2002, 10, 3599-3608.

(24) Maisuria, B. B.; Actis, M. L.; Hardrict, S. N.; Falkinham, J. O.; Cole, M. F.; Cihlar, R. L.; Peters, S. M.; Macri, R. V.; Sugandhi, E. W.; Williams, A. A.; Poppe, M. A.; Esker, A. R.; Gandour, R. D. Comparing micellar, hemolytic, and antibacterial properties of di- and tricarboxyl dendritic amphiphiles. Bioorg. Med. Chem. 2011, 19, $2918-2926$.

(25) Ding, M.; He, X.; Wang, Z.; Li, J.; Tan, H.; Deng, H.; Fu, Q.; $\mathrm{Gu}, \mathrm{Q}$. Cellular uptake of polyurethane nanocarriers mediated by gemini quaternary ammonium. Biomaterials 2011, 32, 9515-9524.

(26) Falsini, S.; Ristori, S.; Ciani, L.; Di Cola, E.; Supuran, CT; Arcangeli, A.; In, M. Time resolved SAXS to study the complexation of siRNA with cationic micelles of divalent surfactants. Soft Matter 2014, 10, 2226-33.

(27) In, S.; Ciani, L.; Candiani, G.; Battistini, C.; Frati, A.; Grillo, I.; In, M. Complexing a small interfering RNA with divalent cationic surfactants. Soft Matter 2012, 8, 749-756.

(28) Muzzalupo, R.; Infante, M. R.; Pérez, L.; Pinazo, A.; Marques, E. F.; Antonelli, M. L.; Strinati, C.; La Mesa, C. Interactions between gemini surfactants and polymers: Thermodynamic studies. Langmuir 2007, 23, 5963-5970.

(29) Brycki, B.; Szulc, A. Gemini alkyldeoxy-D-glucitolammonium salts as modern surfactants and microbiocides: synthesis, antimicrobial and surface activity, biodegradation. PLoS One 2014, 9, No. e84936. 
(30) Obłąk, E.; Piecuch, A.; Krasowska, A.; Łuczyński, J. Antifungal activity of gemini quaternary ammonium salts. Microbiol. Res. 2013, $168,630-638$.

(31) Tan, H.; Xiao, H. Synthesis and antimicrobial characterization of novel l-lysine gemini surfactants pended with reactive groups. Tetrahedron Lett. 2008, 49, 1759-1761.

(32) Ruiz, A.; Pinazo, A.; Pérez, L.; Manresa, A.; Marqués, A. M. Green Catanionic Gemini Surfactant-Lichenysin Mixture: Improved Surface, Antimicrobial, and Physiological Properties. ACS Appl. Mater. Interfaces 2017, 9, 22121-22131.

(33) Zhang, Y.; Ding, M.; Zhou, L.; Tan, H.; Li, J.; Xiao, H.; Li, J.; Snow, J. Synthesis and antibacterial characterization of gemini surfactant monomers and copolymers. Polym. Chem. 2012, 3, 907913.

(34) Paluch, E.; Piecuch, A.; Obłąk, E.; Lamch, E.; Wilk, K. A. Antifungal activity of newly synthesized chemodegradable dicephalictype cationic surfactants. Colloids Surf., B 2018, 164, 34-41.

(35) Piecuch, A.; Obłąk, E.; Guz-Regner, K. Antibacterial Activity of Alanine-Derived Gemini Quaternary Ammonium Compounds. J. Surfactants Deterg. 2016, 19, 275-282.

(36) Masood, M. M.; Irfan, M.; Khan, P.; Alajmi, M. F.; Hussain, A.; Garrison, J.; Rehman, M. T.; Abid, M. 1,2,3-Triazole-quinazolin$4(3 \mathrm{H})$-one conjugates: evolution of ergosterol inhibitor as anticandidal agent. RSC Adv. 2018, 8, 39611-39625.

(37) Aneja, B.; Azam, M.; Alam, S.; Perwez, A.; Maguire, R.; Yadava, U.; Kavanagh, K.; Daniliuc, C. G.; Rizvi, M. M. A.; Haq, Q. M. R.; Abid, M. Natural Product-Based 1,2,3-Triazole/Sulfonate Analogues as Potential Chemotherapeutic Agents for Bacterial Infections. ACS Omega 2018, 3, 6912-6930.

(38) Rowan, R.; Moran, C.; McCann, M.; Kavanagh, K. Use of Galleria mellonella larvae to evaluate the in vivo anti-fungal activity of [Ag2(mal)(phen)3]. BioMetals 2009, 22, 461.

(39) Browne, N.; Hackenberg, F.; Streciwilk, W.; Tacke, M.; Kavanagh, K. Assessment of in vivo antimicrobial activity of the carbene silver(I) acetate derivative SBC3 using Galleria mellonella larvae. BioMetals 2014, 27, 745-752.

(40) McCann, M.; Santos, A. L. S.; Da Silva, B. A.; Romanos, M. T. V.; Pyrrho, A. S.; Devereux, M.; Kavanagh, K.; Fichtner, I.; Kellett, A. In vitro and in vivo studies into the biological activities of 1,10 phenanthroline, 1,10-phenanthroline-5,6-dione and its copper(ii) and silver(i) complexes. Toxicol. Res. 2012, 1, 47-54.

(41) Irfan, M.; Alam, S.; Manzoor, N.; Abid, M. Effect of quinoline based 1,2,3-triazole and its structural analogues on growth and virulence attributes of Candida albicans. PLoS One 2017, 12, No. e0175710.

(42) Reddy, A. R. N.; Reddy, Y. N.; Krishna, D. R.; Himabindu, V. Multi wall carbon nanotubes induce oxidative stress and cytotoxicity in human embryonic kidney (HEK293) cells. Toxicology 2010, 272, $11-16$.

(43) Su, Y.; Hu, M.; Fan, C.; He, Y.; Li, Q.; Li, W.; Wang, L.-h.; Shen, P.; Huang, Q. The cytotoxicity of CdTe quantum dots and the relative contributions from released cadmium ions and nanoparticle properties. Biomaterials 2010, 31, 4829-4834.

(44) Selvaraj, V.; Bodapati, S.; Murray, E.; Blough, E.; Winston, N.; Rice, K.; Shokufar, T.; Zhao, Y. Cytotoxicity and genotoxicity caused by yttrium oxide nanoparticles in HEK293 cells. Int. J. Nanomed. 2014, 9, 1379.

(45) Wayne, P. Reference Method for Broth Dilution Antifungal Susceptibility Testing of Yeasts, Approved Standard; CLSI document M27-A2, 2002.

(46) Aneja, B.; Irfan, M.; Kapil, C.; Jairajpuri, M. A.; Maguire, R.; Kavanagh, K.; Rizvi, M. M. A.; Manzoor, N.; Azam, A.; Abid, M. Effect of novel triazole-amino acid hybrids on growth and virulence of Candida species: in vitro and in vivo studies. Org. Biomol. Chem. 2016, 14, 10599-10619.

(47) Arthington-Skaggs, B. A.; Warnock, D. W.; Morrison, C. J. Quantitation of Candida albicans Ergosterol Content Improves the Correlation between In Vitro Antifungal Susceptibility Test Results and In Vivo Outcome after Fluconazole Treatment in a Murine
Model of Invasive Candidiasis. Antimicrob. Agents Chemother. 2000, 44, 2081-2085. 